\title{
Benefits and pitfalls of social health insurance in pursuit of universal health coverage: lessons for the Eastern Mediterranean
}

\author{
Sameen Siddiqi, ${ }^{7}$ Awad Mataria ${ }^{7}$ and Eduardo Banzon ${ }^{1}$
}

Countries of the Eastern Mediterranean Region (EMR) of the World Health Organization have never been as committed as they are today to ensure that all people have access to needed health services without the risk of financial hardship - the message of universal health coverage (UHC) (1). The average share of out-of-pocket payments for EMR countries stands at around 40\% and in some countries is close to $70 \%$ of total health expenditure (2). This constitutes a major hindrance to pursue the goal of UHC and calls for establishing prepayment and pooling arrangements that guarantee financial protection to all population groups. In their quest for equitable, efficient and sustainable forms of prepayment, countries can choose from multiple arrangements that include allocations from general government revenues, obligatory health insurance, and modalities such as voluntary health insurance and medical saving accounts.

Traditionally, obligatory health insurance financed through premium contributions (from employers and/ or employees) was called social health insurance (SHI), but these days SHI describes a variety of ways of raising and pooling money that involves a mix between obligatory insurance contributions and general government revenues. This change has come about in high-income countries as populations have aged and the ratio of those who pay contributions to those who do not has fallen, so general government revenues have been mixed with obligatory contributions. Similarly, in low- and middle-income countries - with their large informal sector ${ }^{1}$ and vulnerable populations, the concept of SHI has evolved into a prepayment arrangement that is not only funded by premium contributions but also financed from government allocations to subsidize contributions on behalf of the poor and vulnerable populations, including those in the informal sector. Many elements of this new definition of SHI make it an attractive arrangement that countries worldwide are employing or considering implementing. This is also the case with most EMR countries.

In EMR, countries have been distributed into three groups ${ }^{2}$ that are at different stages of introducing or expanding this new vision of raising and pooling funds for health, frequently called SHI. Many countries in Group 2, which are mostly middle income, have a long tradition of obligatory health insurance contributions and have managed to expand coverage to the poor and part of the informal sector using government subsidies; for example, the Islamic Republic of Iran. As an alternate approach, Morocco and Tunisia implement a separate subsidized SHI scheme to cover the poor and vulnerable population. As for Jordan and Palestine, SHI is managed by the Ministry of Health. Despite the multitude of SHI arrangements, the share of out-ofpocket spending remains unacceptably high in many Group 2 countries due to a relatively small benefit package, substantial co-payments, and vulnerable population groups who are not covered. Group 1 or the Gulf Cooperation Council countries rely mainly on general government revenues generated primarily from natural resources to cover a generous package of health services for their citizens. In recent years, Qatar and the United Arab Emirates in particular in Abu Dhabi and Dubai - have shifted from general government revenue to $\mathrm{SHI}$ to cover nationals for all or selected services. The large expatriate populations in these countries are either covered by private health insurance or are granted access to a limited package against nominal payment and in

1 The informal sector covers a wide range of employment categories including the self-employed and those with casual, temporary and unpaid jobs, etc. Source: World Bank http://Inweb90.worldbank.org/eca/eca.nsf/1f3aa35cab9dea4f85256a77004e4ef2/4e4ede543787a0c085256a9 40073f4e4).

2 EMR countries are commonly categorized into three health system groups based on population health outcomes, health system performance and the level of health expenditure. Group 1 (Bahrain, Kuwait, Oman, Qatar, Saudi Arabia, United Arab Emirates); Group 2 (Egypt, Islamic Republic of Iran, Iraq, Jordan, Lebanon, Libya, Morocco, occupied Palestinian territory, Syrian Arab Republic and Tunisia); Group 3 (Afghanistan, Djibouti, Pakistan, Somalia, South Sudan, Sudan and Yemen). 
many cases are left without cover. As for Group 3 countries, Sudan is more advanced in terms of implementing SHI, where the poor and those in the informal sector are partially covered using government subsidies and zakat funds. In these countries, the overall level of financing is inadequate, large segments of the population are not covered and the share of out-of-pocket spending hovers at around $60 \%$ of total health expenditure.

Several features make SHI a powerful instrument for financing the health system and enhancing the move towards UHC. The obligatory nature of SHI results in no opt-outs and ensures social solidarity where the rich, healthy, young and employed subsidize the poor, sick, elderly and unemployed. The clear linkage between contributions and benefits empowers the individuals to demand "paid-for" benefits rather than seek "free" care. Indeed, having an insurance membership card is an enabling tool. Members of SHI are more willing to pay premium contributions as they perceive their payment as a "benefit tax". SHI can improve efficiency by facilitating strategic purchasing. The presence of an independent or quasi-independent fund that enjoys autonomy from the government enables mobilizing money that remains flexible and protected from budgetary negotiations.

If not properly designed or implemented, however, SHI can suffer from several pitfalls. For example, the benefit package may be limited to curative care without emphasis on health promotion and prevention. When implemented in its classical form, SHI may leave out the poorest segments of the population and those in the informal sector. In addition, if fragmented with too many funds, SHI may become inefficient with high administrative costs and delayed reimbursements. High levels of co-payments and low tariffs to attract private providers may perpetuate financial hardship (3).

It is important to recognize the differences between the types of SHI arrangements and the way pooled funds are used to pay for services. When designing obligatory health insurance, it is necessary to consider the package and provider payment methods in ways that ensure efficiency and quality and utilization of services. Countries that attend to these potential pitfalls manage to progress "quickly and surely" towards UHC. The experience of Turkey in merging its five SHI schemes into a single-payer system in less than 10 years, while also integrating its "Green Card" scheme for the poor into the same pool, allowed the country to move closer to UHC (4). Similarly, Thailand, backed by a high level of political commitment, managed to achieve UHC by adding a Universal Coverage scheme for the poor and informal sector, paid entirely from general government revenues. This scheme avoided fee-for-service payments, thereby covering a large population with a wide range of quality services at an affordable cost (5).

While designing or expanding SHI, policy-makers need to ensure that: it remains obligatory and not voluntary for people who can pay, with general government revenues covering those who cannot; it is inclusive and seeks non-riskrelated contributions; the benefit package has a promotive and preventive component; it fosters a single-payer arrangement as far as possible; and it enjoys a degree of autonomy in its implementation to ensure efficiency. SHI means covering not only those who are in the formal sector or those who contribute to payroll taxes but all population groups through government subsidies and other innovative financing mechanisms. Ultimately it is the responsibility of governments to ensure that all people in their countries are protected from the risk of financial catastrophe and impoverishment. SHI is an effective instrument to achieve this goal.

\section{References}

1. The World Health Report 2010. Health systems financing: the path to universal coverage. Geneva: World Health Organization; 2012.

2. Towards universal health coverage: challenges, opportunities and roadmap. Cairo: World Health Organization Regional Office for the Eastern Mediterranean; 2013 (EM/RC60/Tech. Disc.2 Rev.1).

3. Liu X, Tang S, Yu B, Phuong NK, Yan F, Thien DD, et al. Can rural health insurance improve equity in health care utilization? A comparison between China and Vietnam. Int J Equity Health. 2012 (doi: 10.1186/1475-9276-11-10).
4. Atun R, Aydın S, Chakraborty S, Sümer S, Aran M, Gürol I, et al. Universal health coverage in Turkey: enhancement of equity. The Lancet. 2013;382(9886):65-99.

5. Maeda A, Cashin C, Harris J, Ikegami N, Reich M. Universal health coverage for inclusive and sustainable development: a synthesis of 11 country case studies. Washington DC: World Bank Publications; 2014:2-14. 